\title{
PROVIDING CONSUMERS WITH WEB-BASED INFORMATION ON THE ENVIRONMENTAL EFFECTS OF AUTOMOBILES
}

A Qualitative Research Report Based on Focus Groups in Knoxville, Tennessee and Los Angeles, California

Dick Nye

The Looking Glass Group

David Greene

Oak Ridge National Laboratory

Environmental Sciences Division

Janet Hopson

The University of Tennessee

Bo Saulsbury

Oak Ridge National Laboratory

Environmental Sciences Divsion

June 2003

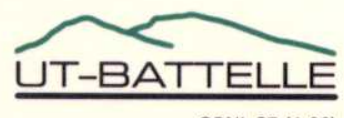




\section{DOCUMENT AVAILABILITY}

Reports produced after January 1, 1996, are generally available free via the U.S. Department of Energy (DOE) Information Bridge.

Web site http://www.osti.gov/bridge

Reports produced before January 1, 1996, may be purchased by members of the public from the following source.

National Technical Information Service

5285 Port Royal Road

Springfield, VA 22161

Telephone 703-605-6000 (1-800-553-6847)

TDD 703-487-4639

Fax 703-605-6900

E-mailinfo@ntis.fedworld.gov

Web site http://www.ntis.gov/support/ordernowabout.htm

Reports are available to DOE employees, DOE contractors, Energy Technology Data Exchange (ETDE) representatives, and International Nuclear Information System (INIS) representatives from the following source.

Office of Scientific and Technical Information

P.O. Box 62

Oak Ridge, TN 37831

Telephone 865-576-8401

Fax 865-576-5728

E-mail reports@adonis.osti.gov

Web site http://www.osti.gov/contact.html

This report was prepared as an account of work sponsored by an agency of the United States Government. Neither the United States Government nor any agency thereof, nor any of their employees, makes any warranty, express or implied, or assumes any legal liability or responsibility for the accuracy, completeness, or usefulness of any information, apparatus, product, or process disclosed, or represents that its use would not infringe privately owned rights. Reference herein to any specific commercial product, process, or service by trade name, trademark, manufacturer, or otherwise, does not necessarily constitute or imply its endorsement, recommendation, or favoring by the United States Government or any agency thereof. The views and opinions of authors expressed herein do not necessarily state or reflect those of the United States Government or any agency thereof. 
Providing Consumers With Web-Based Information on the

Environmental Effects of Automobiles

\section{A Qualitative Research Report Based On Focus Groups in Knoxville, Tennessee and Los Angeles, California}

Dick Nye, The Looking Glass Group

David Greene, Oak Ridge National Laboratory

Janet Hopson, The University of Tennessee

Bo Saulsbury, Oak Ridge National Laboratory

Prepared for

U.S. Department of Energy

Budget Activity Number EE0801000

Prepared by

OAK RIDGE NATIONAL LABORATORY

Oak Ridge, Tennessee 37931

managed by

UT-BATTELLE, LLC

for the

U.S. DEPARTMENT OF ENERGY

under contract DE-AC05-00OR22725

June 2003 



\section{TABLE OF CONTENTS}

ACRONYMS AND ABBREVIATIONS $\ldots \ldots \ldots \ldots \ldots \ldots \ldots \ldots \ldots \ldots$

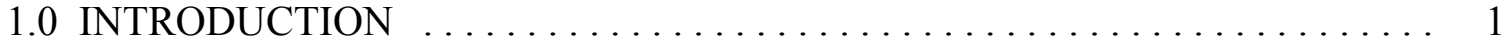

2.0 METHODOLOGY $\ldots \ldots \ldots \ldots \ldots \ldots \ldots \ldots \ldots \ldots \ldots \ldots \ldots \ldots \ldots \ldots$

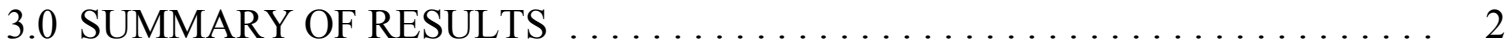

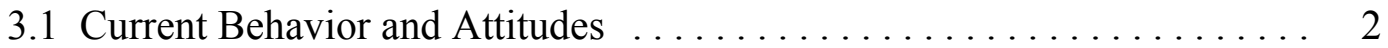

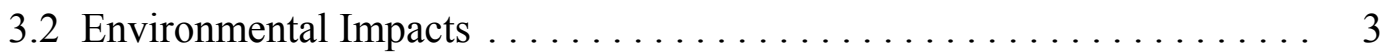

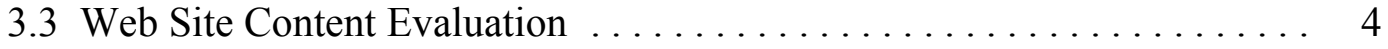

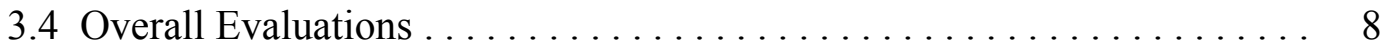

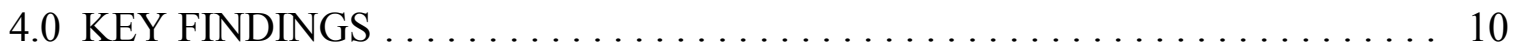

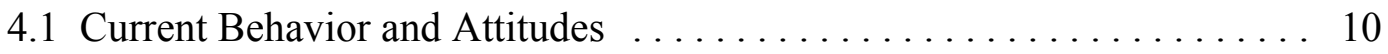

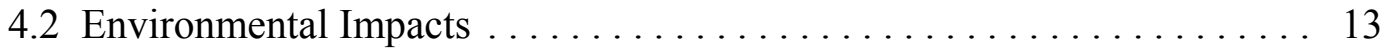

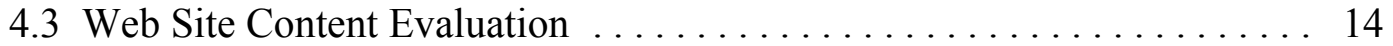

4.3.1 DOE/EPA Web Site ...................... 14

4.3 .2 EPA Web Site $\ldots \ldots \ldots \ldots \ldots \ldots \ldots \ldots \ldots \ldots \ldots \ldots \ldots$

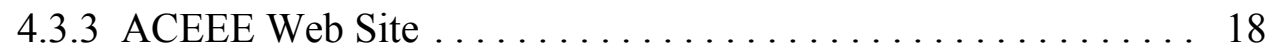

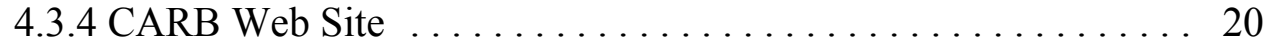

5. CONCLUSIONS, IMPLICATIONS AND RECOMMENDATIONS . . . . . . 22

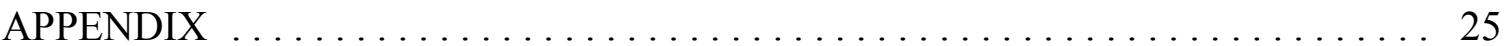





\section{ACRONYMS AND ABBREVIATIONS}

$\begin{array}{ll}\text { ACEEE } & \text { American Council for an Energy-Efficient Economy } \\ \text { CARB } & \text { California Air Resources Board } \\ \text { CFC } & \text { chlorofluorocarbon } \\ \text { DOE } & \text { Department of Energy } \\ \text { EPA } & \text { Environmental Protection Agency } \\ \text { GHG } & \text { greenhouse gas } \\ \text { LEV } & \text { Low Emission Vehicle } \\ \text { MPG } & \text { miles per gallon } \\ \text { NTRC } & \text { National Transportation Research Center } \\ \text { SULEV } & \text { Super Ultra Low Emission Vehicle } \\ \text { SUV } & \text { sport utility vehicle } \\ \text { ULEV } & \text { Ultra Low Emission Vehicle }\end{array}$





\subsection{INTRODUCTION}

The Department of Energy (DOE) and the Environmental Protection Agency (EPA) provide consumers with web-based information on the environmental effects of automobiles so that individuals can make informed choices about the vehicles they use or may purchase. DOE and EPA maintain a web site (www.fueleconomy.gov) that provides users with information about fuel economy [as well as greenhouse gas (GHG) emissions and air pollution emissions] for the cars and trucks they use or may consider purchasing. EPA also maintains a separate web site (www.epa.gov/greenvehicles) that offers similar information, with the focus on air pollution emissions rather than fuel economy. The American Council for an Energy-Efficient Economy (ACEEE) (www.greenercars.com) and the California Air Resources Board (CARB)

(www.arb.ca.gov/msprog/ccbg/ccbg.htm) also maintain web sites that provide consumers with information on the environmental effects of automobiles.

Through the National Transportation Research Center (NTRC) at Oak Ridge National Laboratory, DOE has supported some initial qualitative research with people who are interested in purchasing a new or used vehicle and whose actions identify them as at least somewhat concerned about the environment. ${ }^{1}$ The purpose of this research was to explore and understand how these people respond to the different ratings and measurements of environmental effects provided by the four web sites. The goal of the research is to optimize the communication of information provided on the DOE/EPA web site (www.fueleconomy.gov). Working with a private marketing research firm (The Looking Glass Group of Knoxville, Tennessee), NTRC staff initiated this research by meeting with two focus groups in Knoxville on February 27, 2001. ${ }^{2}$ To obtain information for comparison, staff from the NTRC and the Looking Glass Group also met with two focus groups in Los Angeles, California, on August 13, 2001.

\subsection{METHODOLOGY}

Each of the four focus groups was comprised of respondents between 18 and 64 years of age who (1) gathered information using the Internet, (2) participated in one or more "environmentally friendly" activities, and (3) were in the market for a new or used

${ }^{1}$ The authors gratefully acknowledge the U.S. Department of Energy, Office of Energy Efficiency and Renewable Energy for supporting this research, and Christy Cooper for her guidance and direction. Any errors in the report are the authors' responsibility.

${ }^{2}$ Because human subjects participated in this research, it was conducted under the review and with the consent of the Oak Ridge Associated Universities/Oak Ridge National Laboratory Institutional Review Board (MPA \#1394). 
vehicle within six months. The Appendix to this report contains the screening questionnaire and the recruiting specifications used to identify focus group participants.

Each focus group included seven to ten respondents and lasted approximately two hours. Respondents were asked to view the web sites on their own prior to the group meeting (the CARB web site was used in the Los Angeles sessions only). During the course of each focus group meeting, respondents were shown a "canned" version of each web site that facilitated comparison of the ratings and measurements of fuel economy, air pollution emissions, GHG emissions, and other information provided on each site. The order of presentation among web sites was varied in each focus group to reduce order bias. The focus group sessions were recorded on both videotape and audiotape to help the researchers interpret the results and prepare this report. The Appendix to this report contains the moderator's guide for conducting the focus group meetings.

Among other things, the research was designed to address the following questions:

- What do people know about how cars/trucks affect the environment?

- How have environmental effects influenced their purchase decisions?

- What do people think of the various rating systems employed on the web sites?

- How much information do people want and in what form?

- How might this information affect future purchase decisions?

Before discussing the results of the focus groups, it should be noted that conclusions based on focus group research should be viewed with caution because qualitative research is not designed to be statistically projectable over a large population.

\subsection{SUMMARY OF RESULTS}

\subsection{Current Behavior and Attitudes}

Both the Knoxville and Los Angeles groups indicated that, with the exception of fuel economy, environmental concerns rarely enter into their decision-making process concerning cars or trucks. Even those who do consider fuel economy do so primarily for economic rather than environmental concerns.

There seemed to be a greater sensitivity in Los Angeles than in Knoxville to smog-related issues and the cost of gasoline. There was also a greater, though not universal, awareness of the term Low Emission Vehicle (LEV) in Los Angeles than in Knoxville. However, there was very little understanding in either city of LEV standards, and none of the 
respondents were familiar with the terms Ultra Low Emission Vehicle (ULEV) or Super Ultra Low Emission Vehicle (SULEV).

There was a general perception in all of the groups that increased fuel economy is good for the environment, though respondents did not seem to have a clear sense of why that might be true. This perception seemed to correlate with another one, that the larger the vehicle/engine the worse it is for the environment.

Unlike the Knoxville groups, the Los Angeles groups were already relying on multiple sources for information about motor vehicles (e.g., Consumer Reports, car buff magazines, car shows). Most in Los Angeles indicated that they had previously searched for automobile-related information on-line at web sites such as those maintained by Edmunds and Carfax, as well as on message boards and at auto manufacturers' web sites.

The respondents in both cities said that such web sites were one place they would normally look for objective information prior to venturing into the "untrustworthy" world of the auto dealership. Nonetheless, few had any idea where they would look for information on the environmental effects of automobiles.

The Los Angeles respondents assumed that all vehicles in a given class would be similar in their environmental effects, given the strict state regulations in California. Therefore, they had never considered how one might find or purchase the "cleanest" vehicles (with the exception of electric or hybrid vehicles), and there was considerable confusion about where one would find environmental information on the vehicle itself.

\subsection{Environmental Impacts}

The respondents in both cities seemed to have a strong, but undefined, idea that automobiles are not good for the environment, especially older and larger vehicles and those that are not properly tuned. They knew that tail pipe emissions affect the air we breathe, cause smog, produce acid rain, and affect the ozone, but they did not distinguish between the types of gases emitted and their specific effects. For example, there was very little understanding of the term "greenhouse gases".

Some respondents indicated that they think about the impact of their cars/trucks on the environment, but had not done, or did not know how to do, anything about it. Many seemed to assume that "the government" is regulating the effects of automobiles in some way, and that all vehicles must meet certain government standards. In Los Angeles, the general perception was that the government, especially the State of California, was strictly regulating emissions and fuel economy, and therefore individuals did not need to think about it or take any further action. 
Most respondents indicated that they would like to have some way to compare vehicles on environmental factors, but only a few said this information might significantly affect their purchase decisions.

\subsection{Web Site Content Evaluation}

The respondents gave the information and ratings on the DOE/EPA web site (www.fueleconomy.gov) mixed reviews. Almost no one comprehended the relationship between fuel economy and GHGs (Figure 1). Some respondents found the information about tons of GHGs emitted by each vehicle, and how that related to a "standard" car, to be useful. Others, however, were confused by those numbers and wondered what the "standard" was.

The ratings of pollutants on the DOE/EPA web site were not quite as effective as similar ratings on the EPA site (i.e., simply showing the numbers without the bar graph did not seem as intuitive to respondents; the bar graph shown in Figure 1 has been added in response to this research). For the Los Angeles groups, however, the DOE/EPA site seemed to do the best job of addressing the confusing issue of GHGs. Respondents reacted well to the "best" to "worst" bar chart, though some wondered if there was enough discrimination built into this scale. On the other hand, the number of tons of GHGs emitted per vehicle was so large that it seemed incomprehensible to many respondents.

With the exception of its presentation of the fuel economy numbers, the EPA web site's (www.epa.gov/greenvehicles) Emissions/Air Pollution Rating was the single most understandable, useful and effective measurement for the respondents (Figure 2). The bar chart and 0-10 rating were intuitive and instantly comprehensible to most of the respondents.

Conversely, the EPA site's Green Car Rating (a "five star" system which is no longer used on the EPA site) was confusing and counterintuitive for most respondents. The rating system was not useful without an explanation, and even with an explanation respondents had trouble understanding the formula for producing the star rating, especially the weighting process which places greater emphasis on the lower of two factors (i.e., air pollution emissions or fuel economy). Respondents also found the rating system limiting because it was only applicable within a vehicle's class.

The other summary rating, the ACEEE web site's (www.greenercars.com) Green Score, was intuitive and appealing for most respondents (Figure 3). They appreciated the fact that it was an absolute score across vehicle classes, and could easily see that a " 37 " was better than a "31." However, many respondents had questions about the Green Score and Class Ranking, and the definitions and details on the web site seemed to cause some confusion. Some respondents were skeptical of the subjectivity in calculating the Green 


\begin{tabular}{|c|c|c|c|c|c|c|}
\hline \multicolumn{6}{|c|}{ Use your gas prices } & \multirow[t]{2}{*}{ Switch to Metric units } \\
\hline \multicolumn{6}{|c|}{$\begin{array}{l}2001 \text { Honda Accord } \\
\text { Sorted by MPG (city), Click on column headings to resort }\end{array}$} & \\
\hline & & \multicolumn{2}{|c|}{ MPG } & \multirow{2}{*}{$\frac{\frac{\text { Annual }}{\text { Fuel }}}{\text { Cost }^{*}}$} & \multirow{2}{*}{$\begin{array}{c}\frac{\text { Greenhouse }}{\text { Gas }} \\
\frac{\text { Emissions }}{\text { (tons/yr) }} \\
?\end{array}$} & \multirow{2}{*}{$\begin{array}{l}\frac{\text { EPA Air }}{\text { Pollution }} \\
\text { From } 0 \text { tore } 10 \text { (best) } \\
?\end{array}$} \\
\hline $\begin{array}{l}\text { Compare } \\
\text { up to } 4\end{array}$ & Model & (city) & (hwy) & & & \\
\hline$\Gamma_{\text {compare }}$ & $\begin{array}{l}\text { Honda Accord } \\
4 \text { cyl, } 2.3 \mathrm{~L} \text {, Man( }(5) \\
\text { VTEC, Regular }\end{array}$ & 26 & 32 & $\$ 830$ & 6.8 & \begin{tabular}{r|}
6 \\
7
\end{tabular} \\
\hline$\Gamma_{\text {compare }}$ & $\begin{array}{l}\text { Honda Accord } \\
4 \text { cyl, } 2.3 \mathrm{~L}, \operatorname{Man}(5) \\
\text { Regular }\end{array}$ & 25 & 32 & $\$ 860$ & 7.0 & 6 \\
\hline$\Gamma_{\text {compare }}$ & $\begin{array}{l}\text { Honda Accord } \\
4 \text { cyl, } 2.3 \mathrm{~L} \text {, Auto }(4) \\
\text { VTEC, Regular }\end{array}$ & 23 & 30 & $\$ 895$ & 7.4 & \begin{tabular}{|r|}
6 \\
7 \\
10
\end{tabular} \\
\hline$\square_{\text {compare }}$ & $\begin{array}{l}\text { Honda Accord } \\
\text { cyl, } 2.3 \mathrm{~L}, \text { Auto }(4) \\
\text { Regular }\end{array}$ & 23 & 30 & $\$ 930$ & 7.5 & 6 \\
\hline$\Gamma_{\text {compare }}$ & $\begin{array}{l}\text { Honda Accord } \\
6 \text { cyl, } 3 \text { L, Auto( } 4) \\
\text { VTEC, Regular }\end{array}$ & 20 & 28 & $\$ 1011$ & 8.2 & 6 \\
\hline \multicolumn{7}{|c|}{$\begin{array}{l}{ }^{*} \text { Based on } 45 \% \text { highway driving, } 55 \% \text { city driving, } 15000 \text { annual miles and } \\
\text { the price of fuel used by the vehicle. You may customize these values to } \\
\text { reflect the price of fuel in your area and your own driving patterns. }\end{array}$} \\
\hline
\end{tabular}

Figure 1. Sample page from www.fueleconomy.gov. 


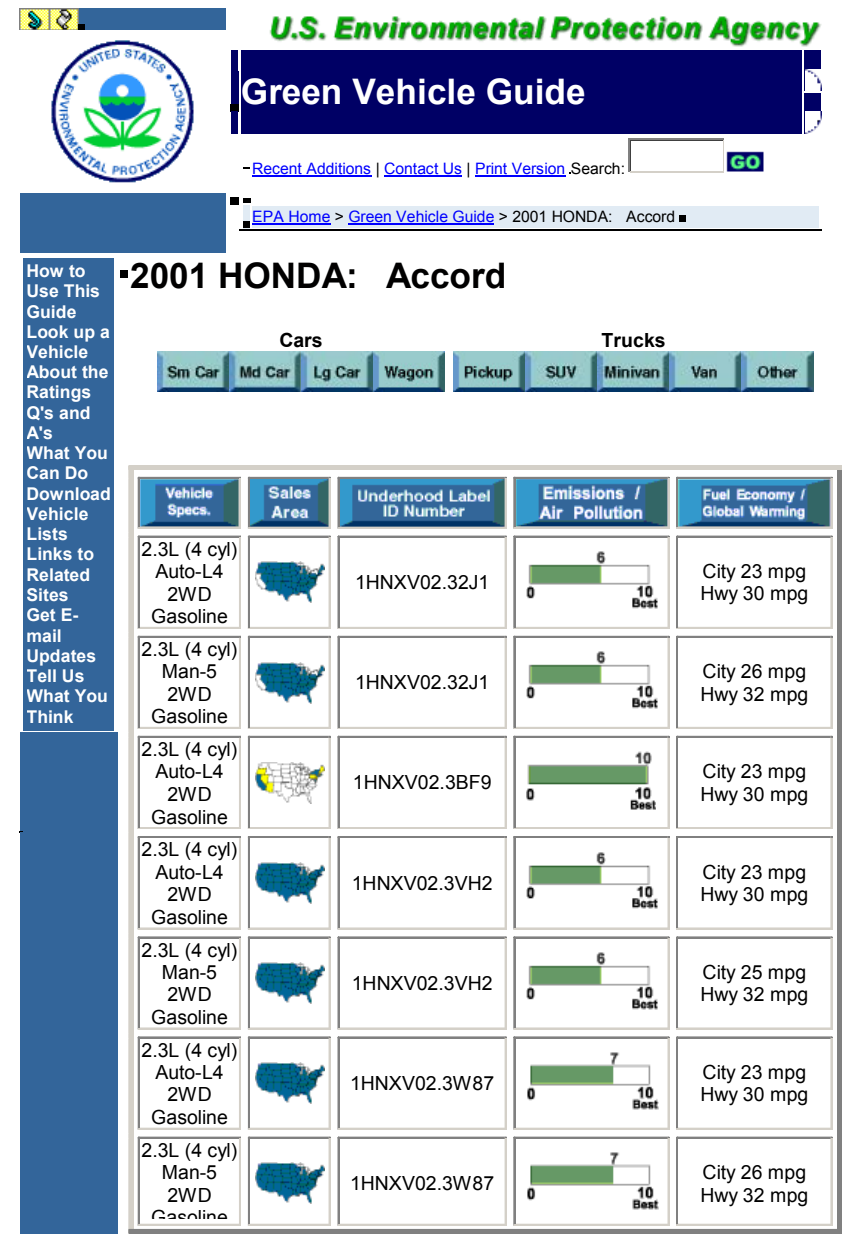

Figure 2. Sample page from www.epa.gov/greenvehicles. 


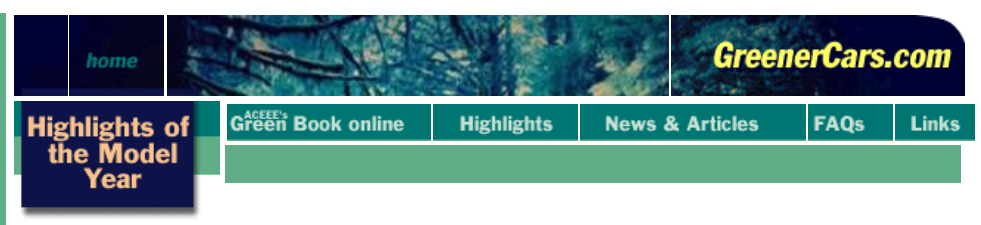

The Best of 2003

The Year's Top-Rated Models in Each Vehicle Class

(For rankings of all model year 2000-2003 vehicles, click here to subscribe to ACEEE's Green Book ${ }^{\circledast}$ Online.)

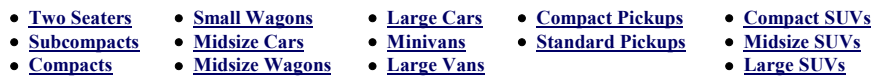

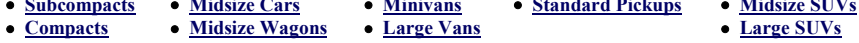

\begin{tabular}{|c|c|c|c|c|c|c|}
\hline \multicolumn{7}{|l|}{ Midsize Cars } \\
\hline Automatics & Specifications & $\begin{array}{l}\text { Emission } \\
\text { Standard }\end{array}$ & $\begin{array}{l}\text { MPG: } \\
\text { City }\end{array}$ & $\begin{array}{l}\text { MPG: } \\
\text { Hwy }\end{array}$ & $\begin{array}{l}\text { Green } \\
\text { Score }\end{array}$ & \begin{tabular}{|l} 
Class \\
Ranking
\end{tabular} \\
\hline HONDA ACCORD & $2.4 \mathrm{~L} 4$, auto & SULEV & 24 & 33 & 37 & Superior \\
\hline TOYOTA CAMRY & $2.4 \mathrm{~L} 4$, auto & SULEV & 23 & 32 & 36 & Superior \\
\hline SATURN L200 & $2.2 \mathrm{~L} 4$, auto & LEV* & 24 & 32 & 31 & Above Avg \\
\hline NISSAN ALTIMA & $2.5 \mathrm{~L} 4$, auto & ULEV* & 23 & 29 & 31 & Above Avg \\
\hline VOLKSWAGEN PASSAT & $1.8 \mathrm{~L} 4$, auto stk [P] & ULEV* & 21 & 30 & 31 & Above Avg \\
\hline MAZDA 6 & $2.3 \mathrm{~L} 4$, auto stk & LEV* $^{*}$ & 23 & 29 & 30 & Above Avg \\
\hline Manuals & Specifications & $\begin{array}{l}\text { Emission } \\
\text { Standard }\end{array}$ & $\begin{array}{l}\text { MPG: } \\
\text { City }\end{array}$ & $\begin{array}{l}\text { MPG: } \\
\text { Hwy }\end{array}$ & $\begin{array}{l}\text { Green } \\
\text { Score }\end{array}$ & \begin{tabular}{|l|} 
Class \\
Ranking
\end{tabular} \\
\hline HONDA ACCORD & $2.4 \mathrm{~L} 4$, manual & LEV* & 26 & 34 & 33 & Superior \\
\hline TOYOTA CAMRY & $2.4 \mathrm{~L} 4$, manual & ULEV* & 23 & 33 & 33 & Superior \\
\hline MAZDA 6 & $2.3 \mathrm{~L} 4$, manual & LEV* & 25 & 32 & 32 & Above Avg \\
\hline NISSAN ALTIMA & $2.5 \mathrm{~L} 4$, manual & ULEV* & 23 & 29 & 32 & Above Avg \\
\hline VOLKSWAGEN PASSAT & $1.8 \mathrm{~L} 4$, manual $[\mathrm{P}]$ & ULEV* & 22 & 31 & 31 & Above Avg \\
\hline SATURN L200 & $2.2 \mathrm{~L} 4$, manual & LEV* $^{*}$ & 23 & 31 & 31 & Above Avg \\
\hline
\end{tabular}

Figure 3. Sample page from www.greenercars.com. 
Score. Others wondered how a car that scored only a "37" out of a possible " 100 " (with the best car on the list rating a "53") could receive a Superior ranking. The credibility of the ACEEE site also suffered from phrases such as "Environmental Damage Index" that seemed to indicate a bias against motor vehicles.

Reactions to the measurements and information presented on the CARB web site (www.arb.ca.gov/msprog/ccbg/ccbg.htm) may have suffered somewhat from the fact that it was shown first in each of the Los Angeles groups. Many respondents seemed to be encountering much of the terminology (e.g., SULEV, engine family number) for the first time, and it took awhile for them to become comfortable with these concepts (Figure 4). Definitions and descriptions on the CARB web site were described as "wordy" and "confusing."

The most useful element of the CARB web site seemed to be the bar chart labeled "Smog Emissions Information." Some respondents also liked the "Know Before You Buy" listing of makes/models listed under the SULEV and ULEV headings, though it took some time before respondents were comfortable with these terms and their definitions. The least useful information on the CARB site was the chart labeled "Passenger Car Emissions Reductions;" respondents found this chart incomprehensible.

\subsection{Overall Evaluations}

The EPA web site's bar graph of Emissions/Air Pollution seemed to be the most intuitive and effective rating system for most respondents. All of the other rating systems had significant weaknesses.

One set of respondents in each focus group preferred some kind of simple, unqualified, overall measure of the environmental impact of vehicles that would apply to all vehicles across all states. However, they were very skeptical of accepting the judgment of government or manufacturers.

Another set of respondents in each focus group, typically those who expressed the most interest in using the information presented in these web sites, preferred information about each individual factor so that they could make their own judgments based on what was most important to them.

The organizations that maintain these web sites have a difficult task because it is apparent that many consumers simply are not interested enough in the type of information presented on the sites to seek it out prior to making their purchase decisions. Many respondents seem to be relying on "the government" to be the environmental watchdogs.

Many respondents indicated that if this environmental information were easily accessible and presented in layman's terms, it would likely help them make a selection from within the set of vehicles that met all of their other criteria. As a result, information needs to be 


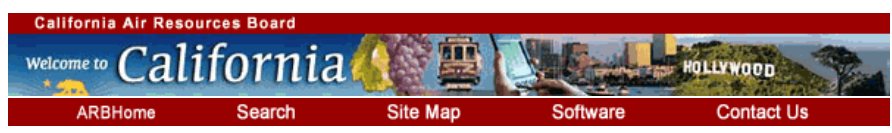

2001 MODEL YEAR GUIDE TO PASSENGER CARS

This page updated April 20, 2001

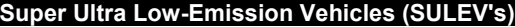

These vehicles are $90 \%$ cleaner than the average new 2001 model year car.

\begin{tabular}{rlllll|} 
Honda & model & displacement & fuel & \multicolumn{2}{c|}{$\begin{array}{c}\text { transmission engine family } \\
\text { number }\end{array}$} \\
\hline Accord* & $2.3 \mathrm{~L}$ & gas & A4 & $1 \mathrm{HNXV02.3BF9}$ \\
$* *$ Civic GX & $1.7 \mathrm{~L}$ & CNG & & $1 \mathrm{HNXV01.7JVH}$
\end{tabular}

Nissan model displacement fuel transmission engine family

$\begin{array}{lllll}\text { Sentra CA* } & 1.8 \mathrm{~L} & \text { gas } & \text { A4 } & \text { 1NSXV01.852A }\end{array}$

Toyota model displacement fuel transmission engine family

$\begin{array}{cclll}\text { Prius* } & 1.5 \mathrm{~L} & \text { gas/EA } & \text { CVT } & \text { 1TYXVO1.5LJ1 }\end{array}$

EA-electric assist

* Gasoline powered vehicles, including hybrid vehicles do not qualify for the (AB 71) single occupant (HOV) carpool lane access sticker, for a current list of qualifying vehicles please click here.

** Alternative fuel vehicle, qualifys for single occupant HOV (carpool) lane access sticker, for a current list of other qualifying vehicles please click here.

Figure 4. Sample page from www.arb.ca.gov/msprog/ccbg/ccbg.htm. 
provided to the consumer in places where they normally expect to find automotive information, or on vehicles themselves. Most indicated that they would, in fact, be likely to access this information on the Internet.

Respondents indicated that most of the information provided on these four web sites is difficult for consumers to comprehend and assimilate. The web sites tend to assume a level of knowledge and interest that does not exist for many consumers. Many of the overall scores and rating systems to which consumers might otherwise gravitate seem to have been created and calculated in ways that make consumers wary and skeptical.

\subsection{KEY FINDINGS}

\subsection{Current Behavior and Attitudes}

The factors that enter into the vehicle purchase decision for Los Angeles respondents appear to be the same as those for Knoxville respondents, suggesting that these factors may be consistent across geographic regions of the country. The factors most frequently mentioned by respondents include (in no particular order): reliability/dependability, safety, utility/function, repair/maintenance history (used vehicles), mileage (used), cost/value, appearance/styling, comfort, performance and fuel economy. The single most important factor for the focus group respondents seemed to be utility/function (i.e., meeting the transportation needs of that particular individual or family). Some respondents had large, or especially tall, families and needed lots of room. Others had a boat to tow, requiring a large engine and heavy vehicle, for example.

"I said I want a car with a third seat in it, so that puts us into a very specific number of cars we're looking at."

"You pick a group and narrow it down to two or three, and if one of them is ugly it falls from the list."

Respondents typically obtain information about these factors from a variety of sources. Those most frequently mentioned include Consumer Reports (most respondents do not subscribe to the magazine, but rather pick up the annual automobile buyers guide), other automobile magazines and source books (e.g. Road and Track, Motor Trend, Kelley Blue Book, etc.), newspaper articles, and car shows. A few individuals in both Los Angeles and Knoxville said they did some automotive research on the Internet.

"When I bought my car, I wanted to know everything about it, so I went on the Internet and looked at fuel economy, different things like that...the Kelley Blue Book to see how much I should pay for it." 
The automobile dealership was typically mentioned as another resource, but the prevailing feeling was that the dealers are biased, that they will provide facts and figures but not any kind of independent evaluation.

"You do all your research up front and then you go to the dealer."

"I think you gather all the information you can before you set foot on the dealer's lot... because you don't get the truth. I think you want to be as educated as you can and it's so easy to just sit at your desk and get all the information you need."

Environmental factors typically did not enter into the purchase decision process for the respondents in either city, with the exception of fuel economy. There was an assumption on the part of many respondents that all vehicles meet some minimum government standards for emissions and that, as a result, they are all the same. Many respondents also assume that there is a correlation between the size of the vehicle/engine and the amount of pollution it emits. Similarly, most assume that the lower the fuel economy, the worse it is for the environment.

"In my way of thinking, the better the gas mileage, the better for the environment."

"To be honest, I don't know if there is a difference in emissions between a Suburban and a Honda Civic. I would think that there was because the Suburban is a bigger car, a bigger engine."

"Probably the volume of emissions is bigger, but they're still meeting the same tail pipe standards."

In both sets of focus groups, there was some mention of fuel economy as a function of cost rather than a concern for environmental damage.

"You look at the mpg because if one is greatly better you consider that. But I view it more from an economic standpoint-spending less on gas."

Beyond those assumptions, there did not appear to be much knowledge among the respondents about environmental factors (a few did mention awareness of the new hybrid vehicles). In fact, there was a good deal of confusion about environmental issues. Several respondents mentioned the debate and politics surrounding global warming, and indicated that they do not want to make personal sacrifices if the concerns about global warming are not real.

"I believe everyone wants to be good citizens and keep our environment clean, but I think a lot of us are guilty. We will put that third, fourth, fifth priority when 
it comes to miles per gallon because you've got to give up something to get emissions, the cost."

For most of the focus group respondents, the potential environmental effects of their vehicle choices are not a factor in their purchase decisions. Most of the respondents assume that large sport utility vehicles (SUVs) cause more pollution or environmental impact than smaller cars, and some said they avoided diesel vehicles because they could see the emissions. Also, there was a great deal of confusion about where they might get such information (prior to being directed to the web sites in this research). Some respondents thought the information might be available from the EPA, in advertisements, magazines, on the window sticker at the dealership, or even in the owner's manual.

Respondents in both cities were also relatively uninformed about how they would go about purchasing an "environmentally friendly" vehicle. Some thought that such vehicles were widely available or easy to order, while others felt that they would be difficult to find because of low demand, except in California. Most of the respondents thought that "green" cars and trucks would be more costly, but some confusion was apparent because respondents indicated that the new hybrid cars were relatively inexpensive. None of the respondents knew how to identify an especially "green" model other than by relying on the information on the window sticker.

The groups from both cities were confused about whether the "cleanest" cars were already available on the dealer's lot, had to be special ordered, or even existed at all. Most respondents agreed that consumers would have to know what they were looking for, could expect to pay more for such vehicles, and that dealers would not provide much help.

"If you're talking about a new car, there's a sticker on the back window that gives you all the information-emissions, gas mileage."

"You don't have to go in necessarily and ask for a low emissions vehicle, for example, with a Civic. That's the way Honda makes them. So, do they stock them because there's a standard Honda and an LEV Honda? No. I think they make them all the same."

Many respondents assumed, however, that various governmental agencies were watching out for the environment by working with (or "pushing") the manufacturers to produce more fuel-efficient and environmentally friendly cars and trucks. Most respondents seem to feel that the manufacturers have made significant progress on reducing automotive pollution. They also recognize that California state regulations on emissions are the most stringent in the nation. Therefore, they assume that all new cars sold in California are already cleaner than those sold elsewhere, and that there are only minor differences between makes and models within any given class. 
"The government puts regulations out that say you have to be under 'this' level if you're going to sell under that car category. So, I figure they're all pretty much the same."

"If I'm looking for a new car you assume that whatever environmental standards are in place, that car has to meet those requirements, and if it meets those requirements that's my thing on the environment."

"I just tend to think that California is so regulated that anything you buy is going to be pretty good. I remember the cars in 1975 and how gross they were and how much better they are now."

\subsection{Environmental Impacts}

The respondents in both cities understood that automobiles and trucks are harmful to the environment in various ways. They recognized that "exhaust from the tail pipe," especially from older and improperly tuned vehicles, causes or contributes to smog, air pollution, acid rain, problems with the ozone layer, and dirt. They also cited oil and fluid leaks, fuel vapors at the gas pump, noise, and even the recyclability of metal and plastic parts on vehicles as affecting water and air quality, plant life, hearing, and scenery. Some of the Knoxville respondents were particularly aware of recent news about air quality problems in the Smoky Mountains and felt that Tennessee needed regulations similar to those in California.

There was a great deal of confusion and a general lack of knowledge, however, about the specific effects of different types of emissions and gases. Some respondents were aware that there were different types of gases emitted, and that a variety of gases were suspect [e.g., carbon monoxide, carbon dioxide, nitrous oxide, chlorofluorocarbons (CFC), etc.]. But most respondents lumped them all together as bad or poisonous.

"It's stuff you don't want to breathe, I know that."

"Anything that's not natural does harm."

When probed about GHGs specifically, the respondents had some familiarity with "the greenhouse effect" from news reports about aerosol cans and CFCs and their effect on the ozone layer. Most respondents, however, had little if any knowledge of what these gases are, how they differ from other pollutants, or how they affect global warming. As a result, many respondents viewed any attempt to use GHGs as a measure of environmental impacts as being subject to confusion, skepticism, and even dismissal.

Most respondents claimed that they want to know how their vehicles affect the environment because they care about air quality. It is unclear, however, whether this type 
of response reflected the "correct" thing to say in the artificial environment of the focus group.

"It's being considerate of others. If we all do a little bit."

Many respondents said they wanted to be able to factor in environmental effects, even if only as a tiebreaker or "bonus" when making their decisions. Some said that environmental information in other consumer areas had already changed their behavior (e.g., abandoning aerosol cans in favor of mechanical pumps). However, many Los Angeles respondents simply could not imagine themselves factoring these concerns into their automotive purchase decision. At best, they could imagine using environmental performance as a tiebreaker. Many said they already pay careful attention to what is on the fuel economy sticker on new cars, and would also like to have some way to compare one vehicle to another based on emissions. Some respondents, claiming to be too busy to seek out detailed information, want to rely on the manufacturer to tell them if the vehicle exceeds government standards. Most seemed to want some type of simple measure, presented in layman's terms, that would allow them to compare emissions from vehicle to vehicle much as they do with fuel economy today. One respondent suggested something similar to the chart that is placed on water heaters, while others mentioned the "circle" system used in Consumer Reports.

"I'm not going to sit and look at all this stuff. I want my car to work and I want it to last and I want it to be child proof, whatever. So, a lot of all this info on the environment I just don't have time for it."

"I wouldn't let environmental friendliness get in the way of a car I wanted to buy."

"If I were looking for a vehicle and two or three met my requirements-all things being equal-one's as stylish as another...my wife approves and we like them... looking at one that was more environmentally friendly would be good."

"I would love to buy something that is environmentally friendly, but I'm stuck with what's there and what my needs are."

"I want it to be available when I want to look it up, and I want someone else thinking about it."

\subsection{Web Site Content Evaluation}

\subsubsection{DOE/EPA Web Site}

Respondents' reactions to the information presented on the DOE/EPA web site were sharply divided. Most respondents liked having both the miles per gallon (MPG) 
numbers and the annual fuel cost displayed together (Figure 1). Some particularly liked the "bullet point" style of presentation, especially the GHG tonnage and how those numbers related to the "standard" car. Other respondents, however, were totally confused by the same GHG numbers and comparisons.

The Los Angeles respondents found several elements of the DOE/EPA site particularly useful. Throughout the meetings, respondents consistently expressed the desire to select and compare vehicles side-by-side. Respondents liked the way information was displayed and the fact that they could see photographs of the vehicles as opposed to simply comparing specifications.

"This one seems to be the most comprehensive. You just need to know what to do with all of the information you get."

On the DOE/EPA web site, the heading "Climate Change" had little meaning for most respondents, apparently because they do not immediately associate cars and trucks with climate change - this heading has been removed as a result of this research. Also, despite the fact that the wording "in tons" was present in the chart, most respondents did not seem to understand what the numbers represented or the "standard" to which they were compared. Some called this chart too scientific, saying that it required too much work to figure out. While a few respondents professed to care about the distinction between GHGs and pollutants, most seemed to think it was more useful to lump them both together as "air pollution" on the web sites.

Compared with the Knoxville groups, the Los Angeles groups found the bar chart measure of GHG emissions to be both comprehensible and useful. Many compared it favorably to the EPA web site's Air Pollution bar chart, and liked the simple "best" to "worst" rating. However, as with the EPA web site's chart, there was some concern that large differences among vehicles tended to be minimized in the DOE/EPA web site's system, so that the difference between a Honda Accord and a Ford Escape appeared to be insignificant to some. The Los Angeles respondents did agree with the Knoxville respondents on the labeling of the charts. While the bar chart appeared to work well, the numbers showing tons of emissions and the explanation of those figures was confusing for most respondents.

"This is helpful if this is a critical factor for you...the most helpful way to have it presented."

"I think this color bar chart was very effective. I think it's very good at getting the information. I think it's real good that they showed the total tons of emissions because it puts in perspective the amount of emissions between the lower polluting ones and the more polluting one. It's a difference, but not as much as you might expect." 
"I can't imagine 7 tons. That's like 14,000 pounds, of what?"

Certain responses to the DOE/EPA web site highlight an inconsistency that confuses many people: many respondents find it disconcerting when high numbers are sometimes good (e.g., the 0-10 Pollutants Rating) and sometimes bad (e.g., GHG Tonnage). As on the EPA web site, the 0-10 Pollutants Rating numbers were easily understood and meaningful to these individuals, and many said this was information that they would be more apt to look at and use. However, the presentation on the DOE/EPA site (as absolute numbers) was not as effective as the EPA site's bar graph - this presentation has been changed as a result of this study.

"If I had this information and it was the same price, I would buy a car that was rated 10 because it lets me know that it exceeds the standard, and the higher the number...I'd be happy with it."

For the Los Angeles groups, the presentation of the Emissions/Air Pollution information on the DOE/EPA site was judged to be ineffective. Even with previous exposure to this measure on the EPA web site, respondents did not fully understand why there were several different bars in the Honda Accord column, for example. The respondents felt that the presentation of this material on the DOE/EPA web site requires consumers to work too hard for information that is intuitive on the EPA web site.

Some Los Angeles respondents were enthused about having access to vehicle safety data on the DOE/EPA web site, even though the focus group moderator had not alerted them to the presence of this information. Their unprompted interest in the safety information highlights the crux of the dilemma for these web sites: consumers seem to be more interested in issues that affect them personally, such as safety, than in more global environmental issues that do not seem to impact them directly or immediately.

"I really appreciate the link to the crash test results because to me that's significantly more important than any emissions thing."

\subsubsection{EPA Web Site}

The EPA web site's U.S. maps showing model availability (Figure 2) were clear to most respondents, but the value of this information seemed questionable since most of these individuals had little idea or concern about availability issues with "green" cars. It did make some ask, however, "If this model is not good enough for California, why is it available everywhere else?" The Los Angeles respondents said the availability maps were interesting, but not tremendously useful.

Information on the "Vehicle ID\#" was both confusing and of questionable value to most respondents. Many assumed this number was the VIN number. Further, they had no idea what the number was for, what it meant, how to use it, or where to find it on the vehicle. 
Very few respondents, if any, were motivated enough to take this number to the dealer and look under the hood to find it. They liked having the "Underhood Label ID Number," however, assuming it was the same as the "engine family number" featured on the CARB web site.

The EPA web site's Emissions/Air Pollution Rating seemed to be the single most intuitive, understandable, useful, and effective rating system of all those included in this study. Respondents in both cities clearly understood the 0-10 scale, although some initially assumed that a lower number relating to emissions reflected lower emissions. They quickly comprehended that this scale related to the relative amounts of emissions coming from the tail pipe. The respondents saw almost immediately that a high score represents cleaner emissions and a more environmentally friendly vehicle. In fact, this rating system had already influenced one of the respondents.

"This was the easiest to deal with."

"I'm not a techie. I like those stars, that's exactly what I went to when I was online, and I thought 'okay, a rating I understand.' This gave me something to think about and I liked what I was seeing."

"One of the sites I looked at...one of the vehicles I was considering, I'm not anymore, just based on this."

There were, however, two consistent criticisms from the Los Angeles respondents. First, in the detail chart showing pounds of air pollution per 15,000 miles that accompanied the bar chart, numbers appeared to have been omitted and the ones that were there did not seem to match up with the bar chart. As a result, this detail chart created more questions than it answered. Second, the Emissions bar chart emphasized the 1-10 scale. Some respondents said that the scale did not allow enough differentiation between vehicles. Most of the cars seemed to cluster around the mid-point, and a car receiving a " 6 " did not seem to be significantly better than one receiving a " 4 ."

On the other hand, the EPA web site's Green Vehicle (five star) Rating was probably the least effective rating system of all that were shown - this rating system has since been removed from the EPA web site. The Green Vehicle Rating system was not at all intuitive and required significant explanation. Respondents were very confused when what seemed to be the same model vehicle with the same mileage figures received different star ratings. Once the rating system was explained during the meeting, most respondents did not like the fact that the lower of two components (i.e., air pollution emissions or fuel economy) was used to develop the overall star rating. It seemed unfair to some respondents that the lower of the two components was used rather than some combination of the two components. These respondents felt that fuel economy might be more important to some consumers, while air pollution might be paramount to others. 
"The problem with the star system is there had to be a weighting giving one (factor) more importance than the other-somebody's opinion on which is more important. If the factors are (shown) separate, it's your decision."

"Now that I'm looking at the other columns, I'm not sure what the stars mean."

"It looks good, but it's not very meaningful."

After seeing an explanation of the Green Vehicle Rating system, a few respondents felt better about it, indicating that using the lower of the two factors was a conservative and credible approach. But, most respondents simply found the equation to be confusing and somewhat unfair.

"What's the point of the Green Vehicle Rating? We have both scores in other columns. Why do they combine them?"

"It's an odd rating system."

"I don't find them very useful."

In addition, many respondents stated that any rating that is only within vehicle class is suspect. They believe that this is a manipulation by the manufacturers designed to make larger vehicles appear more environmentally friendly.

In Los Angeles, reactions to EPA's Green Vehicle Rating were similar to those for ACEEE's Green Score, as respondents gravitated to the star rating because of its familiarity and apparent simplicity. Upon closer inspection, however, respondents found that the number of stars granted to a particular vehicle did not seem to correlate with the Emissions/Air Pollution rating or the Fuel Economy/Global Warming numbers for that vehicle. Most respondents were perplexed, confused, and suspicious.

Some respondents wanted to see the EPA web site's description of the Fuel Economy/Global Warming numbers. This turned out to be one of the easiest definitions for respondents to understand, perhaps because people are already using fuel economy numbers. This explanation helped respondents understand the correlation between burning gasoline and producing GHGs that contribute to global warming.

\subsubsection{ACEEE Web Site}

Respondents found the LEV ratings on the ACEEE web site (Figure 3) to be unclear on first impression, without any explanation or description. Very few could decipher the acronyms. A few respondents indicated having heard the term Low Emissions Vehicle and/or seen it in advertising, but they did not know the definition or standards. Even after the written explanation, however, these respondents only knew that some California 
governmental agency had attached these ratings to certain models. At best, this rating was perceived to be only moderately helpful in comparing one vehicle to another in the same class.

$$
\begin{aligned}
& \text { "It's still kind of confusing." } \\
& \text { "It's not important to me because I don't know what it means." } \\
& \text { "At least it provides a framework. I know that SULEV is better than LEV." }
\end{aligned}
$$

The Los Angeles respondents had the advantage of seeing the CARB web site first, so they were already familiar with the SULEV/ULEV definitions that confused the Knoxville respondents (the CARB web site was not viewed during the Knoxville sessions). In fact, as the Los Angeles respondents became more comfortable with the SULEV/ULEV concept, some suggested that this rating system was the kind of simple, comprehensive measure they needed.

The Green Score on the ACEEE web site was somewhat more intuitive than the LEV labeling, but it was still confusing. Some respondents thought it was a measure of relative damage to the atmosphere or that it was related to emissions, for example. After reading the explanation, some found this system helpful as an absolute measure that was useful across all classes of cars and trucks.

"Someone has gone to the trouble on our behalf to make it easy for us without going crazy doing research."

"It says you get pretty good gas mileage and are not putting too much pollution in the air-not great, but pretty good."

However, other respondents were confused by the ACEEE rating system. One of the biggest issues was the score itself. Given that the highest possible score is "100," many wondered how " 37 " could be considered "superior," and why there would be a 100-point scale when the top score was only "53." In addition, it was not clear how the scores differed; for example, how one model receives a " 35 " when what appears to be the same model with the same specifications receives a " 31. "

"How do they come up with a Superior at 37, and they say the top ranking was 53?"

"Out of 100 that's a 35 and the best is a 53? Where are the rest?"

The other major problem with the ACEEE Green Score was the equation itself. Some respondents liked it because it was so comprehensive ("Everything goes in from start to finish" "A massive undertaking"), but others thought there were too many factors 
included ("This is information overload") or that it depended on some unknown person's judgment. Because not everyone agrees on what is important, these respondents wondered how much faith to put in the number. Some did say that, even with its flaws, the Green Score was "comprehensive," providing a relative measure that allowed consumers to compare scores across all vehicle classes.

It appears that many respondents were inclined to prefer the Green Score because it represents a single, comprehensive summary. Some respondents wanted to see this score on the window sticker of new vehicles. For most respondents, however, this summary score used a lot of information but provided little enlightenment. As a result, it appears the amount of information may be secondary to making the rating system understandable and intuitive to the average person.

Respondents were even more skeptical of the ACEEE web site after viewing details with headings such as Health Cost and Environmental Damage Index. While a few respondents found these numbers of minor interest, most viewed these terms as potentially exaggerated, wondering how these number were derived, and questioned the agenda of the organization sponsoring the site.

"The Environmental Damage Index, it does make me think it's slanted. That terminology hurts the credibility of this information."

"Maybe this organization doesn't like cars at all."

\subsubsection{CARB Web Site}

Although the measures and information presented on the CARB web site were shown first in the Los Angeles focus groups, many of the Los Angeles respondents were unfamiliar with terminology such as Low Emissions Vehicle and Smog Index (Figure 4).

In one Los Angeles group none of the respondents were familiar with Smog Index Labels, while in the other group almost all indicated that they had seen them before. No one seemed to be familiar with the Smog Index, and only a few knew where this label could be found. In general, respondents said they liked this kind of bar chart presentation, comparing it favorably to the ones found on appliances such as water heaters. However, some found this particular bar chart confusing because there was too much information to assimilate.

"I think it's confusing. They took something really technical and tried to make it understandable for the lay public like us. That's why they go, 'cleaner,' 'more polluting.' Than what?"

"I can tell you one thing. It may be listed on the car, but nobody's going to read it." 
CARB's Emissions Reductions chart that provides background detail for the Smog Index Label was perhaps the most troublesome for the Los Angeles respondents of any measure that was presented on the four web sites. Not even an engineer in one of the Los Angeles groups could make sense of the abbreviations and numbers shown.

"I have no idea what this chart is telling me."

"Not a clue. Nothing useful."

"You need a Carl Sagan."

The CARB web site's "Know Before You Buy" listings were initially difficult for respondents to understand, but ultimately proved to be valuable. The respondents initially were totally unfamiliar with the acronyms SULEV and ULEV, and what they meant.

"The only one I've heard of is Low Emissions Vehicle (LEV)."

The written definitions of these terms also proved to be confusing for some respondents, who called it a "word salad." Interestingly, when some respondents learned that virtually all new cars sold in California meet the LEV standard, it actually contributed to their comfort level with what the State government was doing and their lack of interest in searching out the cleanest cars. Some respondents also assumed that SULEV and ULEV cars would be more expensive than the standard or average automobile. Eventually, respondents became more comfortable with this terminology, indicating that they were fairly simple concepts to understand and use.

\section{"It's a good comparison chart."}

Confusion remained, however, about how the same make and model (e.g., Honda Accord) could be listed as both SULEV and ULEV. The respondents wanted to be able to compare competing models side by side, and such anomalies make it difficult to do so.

"What isn't consistent is why the same model of Honda is in both the SULEV and ULEV categories."

Eventually, the respondents understood that there were differences in the "engine family number" for each vehicle, and they surmised that these differences affected the rating somehow. This important information was not readily apparent, however, and it took some time for respondents to reach this conclusion. Even with this information, respondents said they would not know where to find the engine family number on the vehicle, and doubted that the salesman at the dealership would know either.

"The engine family number is the key difference, but we don't know what it refers to." 
"So when I go into the Honda dealership how do I know what I'm getting?"

"It's helpful, but if I'm going to buy a Honda Accord I'm not going to go into the dealer and say, 'I want this engine family number'... before I knew about this... because we're not educated on this."

"I don't think the average salesman would even know about this."

\subsection{CONCLUSIONS, IMPLICATIONS AND RECOMMENDATIONS}

There were very few differences in the attitudes and behaviors of respondents in Knoxville and Los Angeles concerning the environmental effects of automobiles. The respondents in both cities understood some of the environmental effects of producing and operating automobiles, but they rarely factored these effects into the decision process when they considered purchasing a new or used vehicle. Until consumers understand that these environmental effects are issues that affect them personally (such as vehicle safety and the cost of gasoline), they are not as likely to factor environmental concerns into the buying equation.

"I think that for people to start using things like this it's going to take whole shift in mind set."

In Knoxville, there was some sense that the federal government was regulating emissions and fuel economy, but there was also skepticism about governmental motives and regulations. In Los Angeles, there was a much higher level of trust that the government, particularly the State of California, was "on top of" these issues on the consumers' behalf. Recognizing that California's regulations are the most stringent in the nation, Los Angeles respondents were happy to abdicate that responsibility to the State so that they could concentrate on the personal utility and function of their vehicles.

"I want the State and manufacturers to pay attention to that, but as a consumer it's down my list."

The most useful/meaningful information for the respondents tended to be in two areas: fuel economy and some overall rating of tail pipe emissions. Respondents tended to understand the issues of GHGs/global warming more easily when such issues were correlated with familiar concepts (i.e., fuel economy). The distinction between the impacts of different gases appears to be difficult for people to understand and seems somewhat unimportant since the respondents viewed all of the gases as harmful anyway. The issues of GHGs and global warming also seem fraught with confusion, politics, and skepticism, causing many respondents to be apathetic. 
The distinction between smog-producing emissions and GHGs was a new concept for most respondents. Most appear to have accepted the notion that air pollution emissions are a bad thing and that controlling them is a good thing, but there is still considerable controversy surrounding the relationship between GHGs and global warming. As a result, many respondents appear to be reluctant to invest much intellectual energy in understanding this issue or put much stock in measures of its effect.

Most respondents in this study would prefer some kind of overall environmental score that (1) they could have faith in, (2) would be applicable across the country and across all vehicles, and (3) would be displayed on the new car sticker and adopted by magazines such as Consumer Reports.

"If the State came and said, 'This is what you need to get a 4 (stars) or a 3,' I would assume that Ford would not lie to me about which [models] were a 4 or a 3."

Nonetheless, there was a great deal of skepticism among the respondents about the motives and actions of the government, the auto manufacturers, and auto dealers. The most motivated of these respondents would like separate measurements that allow them to make up their own minds about which environmental factors are important to them and how they will influence their purchase decisions.

Most respondents indicated that they would use such information if it were readily available and presented in layman's terms. Wherever a number or term is displayed on these web sites, the appropriate definition or explanation should be presented as well, and the definitions and explanations should be written in simple terms. For many consumers, however, it would be of tertiary value at best. Once some individuals have identified an acceptable set of vehicle makes and models, they might use information about environmental effects to narrow the final choice. This type of information would be much more widely used if it were available where consumers typically go to learn about the cars and trucks they are considering-on the new car sticker or in Consumer Reports or car magazines, for example. Without better marketing, it does not appear that most consumers will know that environmental information exists at these web sites.

Even the consumers for whom environmental information is somewhat important are not likely to dig through the often confusing and conflicting information on a variety of different web sites. Consumers are doing their homework before approaching the dealer, but even with the advent of the Internet they are doing so with standard or expected sources (e.g., Consumer Reports, car magazines, Edmunds.com, manufacturers' web sites, etc.). For environmental information to be considered, it should be available where consumers are searching for related information today.

"That's the answer to your question. How likely am I to use this information in the future? The answer is, 'How hard do I have to dig to get the information?', 
While web site content is paramount, the presentation of what for most people is new or unfamiliar information seems particularly important. It does not appear that many consumers will be willing to spend lots of time navigating through pages of explanation to understand what they are seeing. To the extent possible, each number or rating system should be fully explained within the chart or on the same page. In short, the information needs to be presented in a way that consumers find simple and comprehensible.

Respondents in all four focus groups were naturally drawn to the EPA web site's Green Vehicle Rating system, to easy designations like "superior," and to simple 1-10 scale bar charts for those reasons.

While this study was enlightening and provided a number of valuable insights, it reflects input from a very limited number of people in two markets. Conducting similar focus groups in other geographically different markets would help validate what was learned in Knoxville and Los Angeles. 


\section{APPENDIX}



$\mathrm{Hi}$, my name is with Ackermann Research, a local research organization. I'm not selling anything. Today, we are calling to conduct a brief study and would like to include your opinions. Again, I would like to stress that this is a research study ONLY, and you will not be asked to make any purchases. Everything I ask is solely for research purposes.

Are you over the age of $18 ?$

1. How often on average would you say you use the Internet as a source of gathering information?

Never [THANK \& TERMINATE]

Less than once a Month [CONTINUE]

1-3 times / Month [CONTINUE]

3-10 times/ Month [CONTINUE]

2. Do you or does anyone in your immediate family work for...

An automotive manufacturer, retailer or dealer [THANK

\section{\& TERMINATE]}

An auto supply or parts manufacturer, retailer or dealer [THANK

\section{\& TERMINATE]}

A market research or marketing firm [THANK \& TERMINATE]

The news media [THANK \& TERMINATE]

3. How likely are you to purchase a new or used car in the next 9 months?

[READ]

Very likely

Somewhat likely

Not at all likely [THANK \& TERMINATE] 
4. Which of the following best describe you? (CHECK ALL THAT APPLY) I recycle regularly (weekly or monthly)

I am a member of environmentally active organization (such as The Sierra Club or World Wildlife Fund)

I purchase environmentally friendly products (such as pump spray bottles, recyclable containers)

I consider fuel economy and emissions as an important criteria when selecting a vehicle

None of the above [THANK \& TERMINATE]

5. Which of the following best describes your race or ethnic background?

African American or Black

Caucasian or White

Hispanic or Latino

American Indian

Asian or Pacific Islander

Other

Refused

6. What is your current employment status? Are you:

A homemaker

Working - Full time outside the home

Working - Part Time outside the home

Retired

Unemployed

Student (Full Time)

7. Which of the following categories includes your age?

Under 18 [THANK \& TERMINATE]

18-24

25-34

$35-44$

$45-54$

55-64

$65+$ [THANK \& TERMINATE] 
8. Which of the following best describes the highest level of education you have received? (READ LIST and CHECK THE APPROPRIATE

RESPONSE)

Grade School
Some High School
Graduated High School
G.E.D.
Some College
College Graduate (2yr degree)
College Graduate (Bachelor's Degree)
Post-Graduate Work
Refused

9. Which of the following best describes your marital status? (READ LIST and CHECK THE APPROPRIATE RESPONSE)

\begin{tabular}{c} 
Single \\
Married \\
Divorced \\
\hline Widowed \\
\hline Other
\end{tabular}

10. Which of the following categories best describes the approximate annual income of your family before taxes?

Under $\$ 25,000$

$\$ 25,000$ to $\$ 50,000$

$\$ 50,000$ to $\$ 75,000$

More than $\$ 75,000$

Refused

11. Gender: (do not ask) Male

Female

We would like to invite you to a discussion group regarding the environment. The times available are on Tuesday, February $27^{\text {th }}$ at 6 or $\mathbf{8 P M}$. Which time is better for you? We are conveniently located at the corner of Papermill and Northshore in the NBC building. In appreciation for your time and participation you and the others in the group will each receive $\$ 50$ cash. Refreshments or dinner will be served and the discussion will last $11 / 2$ to 2 hours. 
Now I just need to get your address so I can send you a map and a confirmation letter.

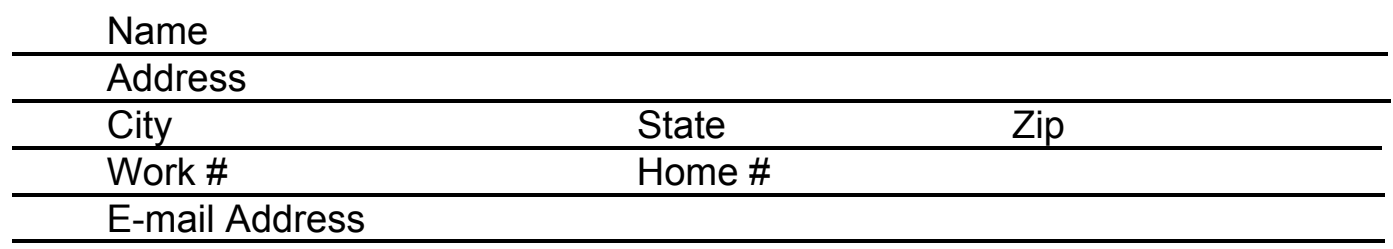

Thanks for your time this evening and we look forward to seeing you on Tuesday, February $27^{\text {th }}$ at .We are counting on you to be there. If you find that you can't attend for some reason, please call Tammy at 588-9280 as soon as possible because we will need to replace you in order to be sure that we have a full group. Thanks, Goodbye!

\section{Reminder call placed and participation confirmed directly with the} respondent:

$\begin{array}{lll}\text { Call Date } & \text { Result } & \text { Initials } \\ \text { Call Date } & \text { Result } & \text { Initials } \\ \text { Call Date } & \text { Result } & \text { Initials } \\ \text { Call Date } & \text { Initials } \\ \text { Call Date } & \text { Result } & \text { Initials } \\ \text { Call Date } & \text { Result } & \text { Initials }\end{array}$




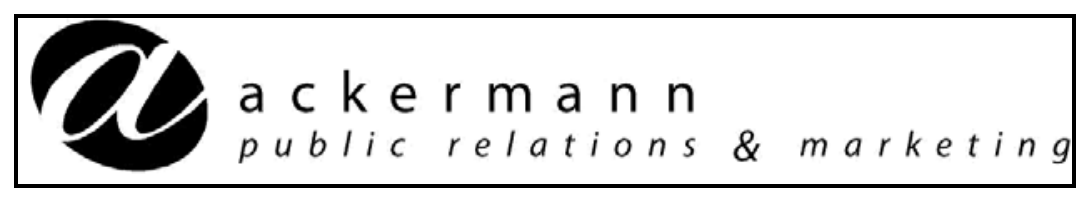

AUDIO/VIDEO RELEASE

I understand this focus group will be audio and video taped. I give Ackermann Research my permission to audio and video tape me during the research process. The video/audio tapes will be used for written reports and may be shared with other individuals involved in the research process.

Signature

Date 


\section{MODERATOR'S GUIDE GREEN CAR FOCUS GROUPS \\ February 2001}

\section{Introduction (10 min.)}

Moderator introduction and ground rules

Respondent introductions (e.g., what they do for a living/with their time, when they last purchased a new or used car, etc.)

\section{Background (20 min.)}

Okay, assume for a moment that you had never looked at the web sites we asked you to look at before this discussion. Now, you're in the market to buy a new or used car or truck, what are the three or four most important things you think about or consider?

Where do you get your information about these factors?

Again, assuming that you had never seen the web sites, what role, if any, does the effect on the environment of the cars/trucks you are considering play on your decision?

Have you ever tried to find any information about how a specific car or truck affected the environment?

How would you have gone about getting information like that...the effect of various vehicles on the environment?

If you wanted to buy one of the cars that has the least environmental impact, how would you go about that? Just go down to the dealer and ask for one?

Do you feel like these cars are generally available?

Is there information on the car somewhere that gives you environmental impact information? Where is it? 


\section{Environmental Impact (15 min.)}

So, how exactly do cars and trucks affect the environment?

Probe for some of the ways specifically that cars/trucks impact the environment (e.g., fuel economy, air pollution emissions, greenhouse gas emissions, recyclability) and the differences between them

Do you think it really matters what make or model of car or truck you buy?

How much did you know about any of this before looking at the web sites?

Would this information seriously affect your car or truck purchase decision, or is it just "nice to know"?

\section{Site Content Evaluation (45 min.)}

Okay, now lets take a look at each of the three web sites we suggested you preview prior to coming tonight and talk about the various rating systems, etc. (Show each web site separately. Take them through the main features of the site, following a similar order in each one, familiarizing respondents with how the rating system works in each case. Rotate the order in each group to eliminate any order bias. After a review of each site, ask:)

Now, after looking at this site, what does this one tell you about which cars/trucks are best for the environment?

How does it do that? What measurements does it use?

Probe the specifics and relative merits of each site's measurements (e.g., 0-10 rating, five star rating, fuel economy, tons of greenhouse gas emissions, etc.)

Probe what environmental factors or impacts are included in, and left out of, those measurements

Probe how meaningful/helpful each measurement is

Probe the strengths and weaknesses of each measurement 


\section{Overall Evaluations (20 $\mathrm{min}$.)}

(After all three sites reviewed, ask:)

Okay, now that you have reviewed all three sites, which measure of environmental impact did you find most meaningful and useful?

Probe reasons why

Do you like a single measure ("Best Friends of the Environment", for example), or is it more useful to have a separate measure for each major factor...like fuel economy, air pollutants, greenhouse gases, etc.?

What would have made these measurements and ratings better, more useful and meaningful to you?

Can you envision yourself really using this information in deciding which car or truck to buy? If so, how would you use it? If not, why not?

Is the Internet a good place for this information to be available to people?

Is there a better or different way this information could be presented or available that would make it more useful to you?

(Developed by the moderator, Dick Nye, 865-525-2379, 900 S. Gay St., Ste. 2309, Knoxville, TN 37902) 
INTERNAL DISTRIBUTION

1. J. W. Saulsbury

2-3. ESD Library

4. Office of Technical Information and Classification

\section{ELECTRONIC DISTRIBUTION}

baindt@ornl.gov

christy.cooper@hq.doe.gov

foxec@ornl.gov

dlgreene@ornl.gov

hildebrandsg@ornl.gov

hopsonj1@ornl.gov

jacobsgk@ornl.gov

lookingglass@itilink.com

saulsburyjw@ornl.gov

zimmermangp@ornl.gov 